\title{
Potencial de silagens de ramas de batata-doce para alimentação animal
}

\author{
Potential of silages of sweet-potato foliages for animal feeding
}

\section{Daniel José Silva Viana ${ }^{\mathrm{I}}$ Valter Carvalho de Andrade Júnior ${ }^{\mathrm{I}}$ Karina Guimarães Ribeiro \\ Nísia Andrade Villela Dessimoni Pinto ${ }^{\mathrm{II}}$ Irã Pinheiro Neiva ${ }^{\mathrm{I}}$ José Altair Figueiredo $^{\mathrm{I}}$ Vinícius Teixeira Lemos ${ }^{I}$ Carlos Enrrik Pedrosa $^{I}$ Alcinei Místico Azevedo $^{\mathrm{I}}$}

\section{RESUMO}

Objetivou-se avaliar o potencial de silagens de ramas de diferentes clones de batata-doce para alimentação animal. O trabalho foi realizado na Fazenda Forquilha localizada no Distrito de Batatal, município de Diamantina $M G$, no período de 23/12/2007 a 23/06/2008. O experimento foi conduzido no esquema de parcelas subdivididas em delineamento de blocos completos casualizados. Foram avaliadas a produtividade de matéria verde e matéria seca das ramas e a composição químico-bromatológica, além do perfil fermentativo de suas silagens, em três idades de colheita (120, 150 e 180 dias), em oito clones de batata doce. A produtividade de matéria seca não variou com a época de colheita das ramas, obtendo-se média de 6,01t ha $\mathrm{h}^{-1}$. Os teores de matéria seca nas ramas aumentaram com o ciclo da cultura, verificando-se teores médios de 11,94; 12,16 e 19,62\%, aos 120, 150 e 180 dias após o corte, respectivamente. As silagens das ramas de batata-doce apresentaram altos teores protéicos e energéticos $e$ adequado perfil fermentativo, portanto, apresentam potencial para utilização na alimentação animal, independentemente dos clones.

Palavras-chave: fibra em detergente neutro, nitrogênio amoniacal, $\mathrm{pH}$, produtividade de matéria seca, proteína bruta.

\section{ABSTRACT}

The objective was to evaluate the potential of silage derived from different clones of sweet potato for animal feed. The study was conducted at Forquilha Farm located in Batatal district, MG Diamantina in the period from 23/12/2007 to 23/ $06 / 2008$. The experiment was conducted in split plot design in a randomized complete block. It was evaluated the green and dry matter yield, the chemical composition and the fermentative profile of silage harvested on three dates (days 120, 150 and 180), of eight clones of sweet potato. The dry matter yield did not vary according to the harvest time of the branches, resulting in an average of 6.01t ha $\mathrm{h}^{-1}$. The dry matter content in the stems increased with the growth cycle, and there are average levels of $11.94,12.16$ and $19.62 \%$ on days 120, 150 and 180 after cutting, respectively. The raw potato silage showed high protein content and adequate energy fermentation and therefore, potential for use in animal feed, regardless of clones.

Key words: neutral detergent fiber, ammonia nitrogen, $\mathrm{pH}$, dry matter yield, crude protein.

\section{INTRODUÇÃO}

A batata-doce é considerada uma espécie rústica e uma cultura bastante disseminada em toda região brasileira, de certa relevância econômica e uma hortaliça de ampla aceitação popular, sendo cultivada na maioria das vezes por pequenos produtores rurais em sistemas agrícolas, com reduzida utilização de insumos (SOUZA, 2000).

As ramas de batata-doce, por possuírem alta porcentagem de proteína bruta, em torno de $12,6 \%$ (BARREIRA, 1986), e boa digestibilidade, possibilitam que sejam usadas principalmente na alimentação de gado leiteiro, tanto na forma fresca ou como silagem (MONTEIRO, 2007), atuando inclusive como estimulante da produção láctea (PUPO, 1985).

'Programa de Pós-graduação em Produção Vegetal, Universidade Federal dos Vales do Jequitinhonha e Mucuri (UFVJM), Campus JK, Rodovia MGT 367, Km 583, nº 5000, Alto da Jacuba, 39100-000, Diamantina, MG, Brasil. E-mail: daniel.silva@ufvjm.edu.br.

*Autor para correspondência.

"Departamento de Nutrição, UFVJM, Diamantina, MG, Brasil. 
Entre as soluções utilizadas para o armazenamento de forragens, ressalta-se a confecção de silagens, uma vez que esta é uma prática relativamente simples e com finalidade de suprir a alimentação animal nas épocas estratégicas do ano (FREITAS et al., 2005).

MASSAROTO (2008), avaliando clones de batata-doce para alimentação animal, verificou que a cultura da batata-doce tem um grande potencial para utilização, tanto na forma de ramas, como também na forma de silagem, na qual as silagens de ramas dos clones avaliados apresentaram valores de $\mathrm{pH}$ dentro do padrão ideal, proteína bruta variando de 9,6 a 13,2\%, fibra em detergente neutra entre 37,9 a 58,2\% e matéria seca variando de 16,0 a 26,3\% .

As cultivares recomendadas estão estreitamente relacionadas com o local e época de plantio, adubação e finalidade de produção. São escassos os trabalhos de pesquisa visando a selecionar e indicar cultivares para as diferentes regiões do país, melhores épocas de colheita, e, ainda, conhecer as características dessas cultivares, que venham garantir sua utilização na alimentação animal. Sendo assim, objetivou-se com este trabalho avaliar características produtivas e qualitativas da forragem fresca e da silagem de diferentes clones de batata-doce, visando à alimentação de ruminantes.

\section{MATERIAL E MÉTODOS}

O trabalho foi realizado na Fazenda Forquilha (altitude 1219m, 18³1'31''S e 4351'19'W), em um Neossolo Quartzarênico Órtico típico (EMBRAPA, 2006), localizada no Distrito de Batatal, município de Diamantina - MG no período de 23/12/2007 a 23/06/2008.

$\mathrm{O}$ experimento foi conduzido no esquema de parcelas subdivididas no delineamento em blocos completos casualizados, dispondo-se de três idades de colheita (120, 150 e 180 dias) nas parcelas e oito clones nas subparcelas, com três repetições, no total de 72 unidades experimentais, com $4,5 \mathrm{~m}^{2}$ cada e espaçamento de $1,0 \mathrm{~m}$ entre linhas (camalhões) e $0,30 \mathrm{~m}$ entre plantas. Os clones avaliados fazem parte do banco de germoplasma da UFVJM, sendo: BD-38, BD-45, BD25, BD-31TO, BD-15, BD-08 e as cultivares 'Brazlândia Rosada' e 'Princesa'.

Para a coleta das ramas, a parte aérea foi cortada rente ao solo no momento da colheita aos 120, 150 e 180 dias após o plantio. Em seguida, foram retiradas subamostras das ramas para posteriores análises laboratoriais.

A produtividade de matéria verde foi obtida através da pesagem das ramas colhidas nas parcelas de cada tratamento e os resultados foram expressos em t ha ${ }^{-1}$. Para cálculo do teor de matéria seca, foram retiradas subamostras das ramas que foram pesadas, colocadas em sacos de papel e secas em estufa com ventilação forçada, a $60^{\circ} \mathrm{C}$, até atingir peso constante. Os teores de matéria seca foram calculados, dividindose os valores da massa seca pelos valores de massa verde e multiplicados por 100. A produtividade de matéria seca foi obtida pelo produto entre a produtividade de matéria verde $\left(\mathrm{t} \mathrm{ha} \mathrm{h}^{-1}\right)$ e o teor de matéria seca, sendo os resultados expressos em $\mathrm{t} \mathrm{ha}^{-1}$.

Para a obtenção da silagem, a parte aérea foi cortada rente ao solo, no momento da colheita da raiz somente na segunda idade de colheita (150 dias após o plantio), e emurchecidas em ambiente coberto durante doze dias na Fazenda Forquilha. As ramas foram picadas em um desintegrador com tamanhos de partículas em torno de $2 \mathrm{~cm}$ e ensiladas em 24 silos de PVC, com $50 \mathrm{~cm}$ de altura e $10 \mathrm{~cm}$ de diâmetro, providos com válvula de Bünsen e lacradas com fita de PVC. A abertura dos silos foi realizada aos 45 dias da ensilagem, sendo retiradas amostras de silagem da porção central do silo, que foram congeladas para a realização das análises.

Para avaliação da qualidade da silagem foram realizadas as seguintes análises: proteína bruta, fibra em detergente ácida, fibra em detergente neutra, hemicelulose, nutrientes digestíveis totais, nitrogênio amoniacal em relação ao nitrogênio total e pH.

As fibras em detergente ácido (FDA) e detergente neutro (FDN) foram determinadas por meio do método proposto por VAN SOEST (1967). A hemicelulose foi obtida pela diferença entre FDN e FDA. Os teores de nutrientes digestíveis totais (NDT) foram obtidos utilizando-se a equação $\% \mathrm{NDT}=\% \mathrm{~PB}+\% \mathrm{FB}+(\% \mathrm{EEx} 2,25)+\% \mathrm{ENN}$, sendo $\% \mathrm{ENN}=100-(\% \mathrm{UMIDADE}+\% \mathrm{~PB}+\% \mathrm{FB}+\% \mathrm{EE}+\% \mathrm{MM})$, conforme descrito por SILVA \& QUEIRÓZ (2002). O nitrogênio amoniacal em relação ao nitrogênio total foi determinado pelo método Kjeldahl, segundo técnica da AOAC (1990). O pH foi determinado por potenciometria em eletrodo de vidro, segundo técnica da AOAC (1990).

Todos os dados foram submetidos à análise de variância e as médias dos tratamentos foram comparadas utilizando-se o teste Tukey, adotando-se o nível de 5\% de probabilidade. Apesar de o experimento ter sido conduzido no esquema de parcelas subdivididas, os dados foram analisados em esquema fatorial no delineamento em blocos completos casualizados.

\section{RESULTADOS E DISCUSSÃO}

Não houve interação entre clone e época de colheita para produtividade de matéria verde, produtividade de matéria seca e teor de matéria seca das ramas (Tabela 1), assim como não houve diferença 
Tabela 1 - Resumo da análise de variância de produtividade de matéria verde, produtividade de matéria seca e teor de matéria seca de ramas frescas de clones de batata-doce. UFVJM, Diamantina, MG, 2008.

\begin{tabular}{|c|c|c|c|c|}
\hline $\mathrm{FV}$ & GL & Produtividade de matéria verde & Produtividade de matéria seca & Teor de matéria seca \\
\hline Clone & 7 & $628.788320 * *$ & $11.434909 * *$ & $10.277787^{\mathrm{ns}}$ \\
\hline Época & 2 & $3351.246860 * *$ & $0.742506^{\mathrm{ns}}$ & $458.823976^{* *}$ \\
\hline ClonexÉpoca & 14 & $193.839798^{\mathrm{ns}}$ & $3.926256^{\mathrm{ns}}$ & $2.684405^{\mathrm{ns}}$ \\
\hline Resíduo & 46 & 195.087708 & 3.328497 & 5.425034 \\
\hline Bloco & 2 & $1654.195443 * *$ & $13.657426^{*}$ & $31.452793 * *$ \\
\hline
\end{tabular}

*Significativo a $5 \% \quad * *$ significativo a $1 \% \quad{ }^{\text {ns }}$ Não significativo

significativa para teor de matéria seca entre os clones apresentando valor médio de $14,57 \%$. Já para os valores de matéria seca nas diferentes épocas de colheita, observaram-se maiores valores na terceira época $(19,62 \%)$ comparativamente $(\mathrm{P}<0,05)$ às duas primeiras épocas de colheita.

Foi observada diferença significativa a 5\% para o fator clone, para as características produtividade de matéria verde e produtividade de matéria seca das ramas. Já para o fator época, foi observada diferença para produtividade de matéria verde e teor de matéria seca (Tabela 1).

Entre as variáveis analisadas na silagem das ramas da batata-doce (Tabela 2), apenas os teores de hemicelulose apresentaram diferenças entre os clones.

A produtividade de matéria verde variou de 18,52 a 64,62t ha-1. Em média, o clone BD-31TO foi o que obteve a maior produtividade de matéria verde, $59,78 \mathrm{t} \mathrm{ha}^{-1}$ (Tabela 3 ), não diferindo dos demais clones, com exceção do clone BD-25 e da cultivar 'Princesa', apresentando valores médios de 32,59 e $36,98 \mathrm{t} \mathrm{ha}^{-1}$, respectivamente. CARDOSO et al. (2005) encontraram valores de produtividade de matéria verde bem inferiores, variando entre 1,4 a $14,1 \mathrm{t} \mathrm{ha}^{-1}$. Já MASSAROTO (2008) obteve produtividade de matéria verde entre 7,6 e 50,0t ha ${ }^{-1}$ quando colhidos aos 180 dias após o plantio.

A produtividade de matéria verde obtida aos 120 e 150 dias após o plantio foi de 50,36 e 52,77 tha ${ }^{-1}$, respectivamente, não deferindo significativamente entre si, mas esses resultados foram superiores à produtividade obtida aos 180 dias, que foi de $31,20 \mathrm{tha}^{-1}$, sugerindo que, para obtenção de maiores produtividades de matéria verde, as ramas devem ser colhidas até os 150 dias após o plantio.

A produtividade de matéria seca de ramas dos clones variou de 4,82 a 7,88t ha-1 (Tabela 3). Não foram observadas diferenças na produtividade de matéria seca entre os períodos de colheita, ou seja, a época de colheita não influenciou na produtividade de matéria seca.

Houve diferença significativa entre os clones apenas aos 180 dias após a colheita, momento em que os clones BD-31 TO, BD-45, BD-08 e as cultivares 'Brazlândia Rosada' e 'Princesa' foram os que apresentaram as maiores produtividades de

Tabela 2 - Resumo da análise de variância de teores (\%) médios de matéria seca (MS), fibra em detergente ácido (FDA), fibra em detergente neutro (FDN), hemicelulose $(\mathrm{HC})$, proteína bruta $(\mathrm{PB})$, nitrogênio amoniacal em relação ao nitrogênio total $\left(\mathrm{N}-\mathrm{NH}_{3} / \mathrm{N}-\mathrm{TOTAL}\right)$, nutrientes digestíveis totais (NDT) e valores de $\mathrm{pH}$ de silagem de ramas de clones de batata-doce. UFVJM, Diamantina, MG, 2008.

\begin{tabular}{|c|c|c|c|c|c|}
\hline FV & GL & MS (\%) & FDA $(\%)$ & FDN (\%) & $\mathrm{HC} \%)$ \\
\hline Clone & 7 & $12.225102^{\mathrm{ns}}$ & $3.225238^{\mathrm{ns}}$ & $4.153914^{\mathrm{ns}}$ & $1.951176^{* *}$ \\
\hline Bloco & 2 & $7.934197 *$ & $3.012917^{\mathrm{ns}}$ & $2.174271^{\mathrm{ns}}$ & $0.422068^{*}$ \\
\hline Erro & 14 & 35.104287 & 1.933631 & 2.087604 & 1.641354 \\
\hline & & $\mathrm{PB}(\%)$ & $\mathrm{N}-\mathrm{NH}_{3} / \mathrm{N}-\mathrm{TOTAL}(\%)$ & $\operatorname{NDT}(\%)$ & $\mathrm{pH}$ \\
\hline Clone & 7 & $1.641788^{\mathrm{ns}}$ & $0.204667^{\mathrm{ns}}$ & $1.940461^{\mathrm{ns}}$ & $0.005476^{\mathrm{ns}}$ \\
\hline Bloco & 2 & $0.757272^{\mathrm{ns}}$ & $0.267208^{\mathrm{ns}}$ & $1.187638^{\mathrm{ns}}$ & $0.003750^{\mathrm{ns}}$ \\
\hline Erro & 14 & 1.182529 & 0.395879 & 0.878347 & 0.002798 \\
\hline
\end{tabular}

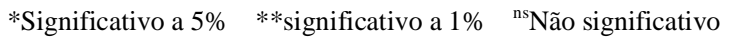


Tabela 3 - Valores médios de produtividade de matéria verde e produtividade de matéria seca de ramas frescas de clones de batata-doce em diferentes épocas de colheita. Diamantina, MG, UFVJM, 2008.

\begin{tabular}{|c|c|c|c|c|}
\hline Clones & 120 dias & 150 dias & 180 dias & Média \\
\hline Braz. Rosada & $53,96^{\mathrm{AB}}$ & $60,59^{\mathrm{A}}$ & $28,81^{\mathrm{B}}$ & $47,79^{\mathrm{ab}}$ \\
\hline Princesa & $43,85^{\mathrm{A}}$ & $29,74^{\mathrm{A}}$ & $37,34^{\mathrm{A}}$ & $36,98^{\mathrm{b}}$ \\
\hline BD-08 & $61,85^{\mathrm{A}}$ & $56,37^{\mathrm{AB}}$ & $30,22^{\mathrm{B}}$ & $49,48^{\mathrm{ab}}$ \\
\hline BD-15 & $43,40^{\mathrm{AB}}$ & $56,56^{\mathrm{A}}$ & $22,30^{\mathrm{B}}$ & $40,75^{\mathrm{ab}}$ \\
\hline BD-25 & $35,33^{\mathrm{A}}$ & $43,93^{\mathrm{A}}$ & $18,52^{\mathrm{A}}$ & $32,59^{\mathrm{b}}$ \\
\hline BD-31 TO & $64,52^{\mathrm{A}}$ & $62,67^{\mathrm{A}}$ & $52,15^{\mathrm{A}}$ & $59,78^{\mathrm{a}}$ \\
\hline BD-38 & $48,45^{\mathrm{AB}}$ & $60,26^{\mathrm{A}}$ & $22,15^{\mathrm{B}}$ & $43,62^{\mathrm{ab}}$ \\
\hline BD-45 & $51,48^{\mathrm{A}}$ & $52,07^{\mathrm{A}}$ & $38,15^{\mathrm{A}}$ & $47,23^{\mathrm{ab}}$ \\
\hline Média & $50,36^{\mathrm{A}}$ & $52,77^{\mathrm{A}}$ & $31,20^{\mathrm{B}}$ & 44,78 \\
\hline $\mathrm{CV}$ & \multicolumn{4}{|c|}{$31,19 \%$} \\
\hline Braz. Rosada & 7,44 & 7,40 & $5,68^{\mathrm{ab}}$ & $6,84^{\mathrm{ab}}$ \\
\hline Princesa & 5,13 & 3,69 & $6,90^{\mathrm{ab}}$ & $5,24^{\mathrm{ab}}$ \\
\hline BD-08 & 7,38 & 7,29 & $6,58^{\mathrm{ab}}$ & $7,08^{\mathrm{ab}}$ \\
\hline BD-15 & 4,54 & 5,94 & $4,19^{\mathrm{b}}$ & $4,89^{\mathrm{b}}$ \\
\hline BD-25 & 4,49 & 5,78 & $4,19^{\mathrm{b}}$ & $4,82^{\mathrm{b}}$ \\
\hline BD-31TO & 7,45 & 6,70 & $9,48^{\mathrm{a}}$ & $7,88^{\mathrm{a}}$ \\
\hline BD-38 & 5,57 & 6,81 & $4,09^{\mathrm{b}}$ & $5,49^{\mathrm{ab}}$ \\
\hline BD-45 & 5,41 & 6,07 & $6,00^{\mathrm{ab}}$ & $5,83^{\mathrm{ab}}$ \\
\hline Média & 5,93 & 6,21 & 5,89 & 6,01 \\
\hline $\mathrm{CV}$ & & & & \\
\hline
\end{tabular}

Médias seguidas pela mesma letra minúscula nas colunas e maiúscula nas linhas não diferem entre si pelo teste "Tukey”, em nível de 5\% de probabilidade.

matérias seca, com valores de produtividade variando de 5,68 a 9,48t ha-1. Os clones BD-38, BD-15 e BD-25 foram os que apresentaram as menores produtividades com valores de 4,09, 4,19 e 4,19t ha ${ }^{-1}$ respectivamente, diferindo significativamente dos demais clones, mas não diferindo entre si. CONCEIÇÃO et al. (2004) verificaram uma redução na produtividade de matéria seca das ramas de batata-doce quando a colheita é feita mais tardiamente. MASSOROTO (2008) encontrou produtividade de matéria seca de ramas de batata-doce variando de 0,8 a $7,2 \mathrm{tha}^{-1}$.

Os teores de matéria seca nas ramas variaram de 10,49 a 21,74\%. Os clones quando colhidos aos 180 dias após o plantio (Tabela 4) apresentaram maiores teores de matéria seca, entretanto, não houve diferença nos teores de matéria seca entre clones. Verificou-se que os teores de matéria seca nas ramas aumentam com o ciclo da cultura. MASSAROTO (2008) encontrou teores de matéria seca de ramas de batatadoce variando entre 11,5 a $17,5 \%$.

Os teores de matéria seca das silagens nos diferentes genótipos variaram de 18,48 a 23,09\%, não havendo diferença entre os genótipos, que apresentaram média de 20,40\%. Os teores de matéria seca encontrados são considerados baixos para a produção de silagens, para as quais se recomendam teores próximos de 30\% (VALVASORI et al., 1995).

Os valores de FDA variaram de 36,50 a $39,43 \%$ e os de FDN de 43,83 a 47,57\% com médias de 46,17 e $38,39 \%$, respectivamente. QUEIROZ et al. (2008) encontraram valores de FDA para silagem de cana-deaçúcar e de milho de 30,52 e 29,91\%, respectivamente. WANDERLEY et al. (2002) encontraram valores de FDA e FDN para silagem de sorgo de 35,06 e 65,12\%, respectivamente. REZENDE et al. (2002), avaliando silagem de girassol, encontraram valores de FDN entre 33,65 e 50,69\%. SENGER et al. (2005), avaliando os efeitos do teor de matéria seca ao corte e da compactação de silagens de milho, encontraram, para a silagem bem compactada, teores de $20 \%$ de matéria seca, 62,3\% de FDN e 38, $\%$ de FDA.

Os clones BD-15, BD-38, BD-25, BD-08, BD45 e a cultivar 'Princesa' foram os que apresentaram os maiores teores de hemicelulose, não havendo diferença eles. Todos os clones apresentaram baixos valores de hemicelulose, variando de 6,65 a 8,95\%. VELHO et al. 
Tabela 4 - Teores médios da matéria seca de ramas de diferentes clones de batata-doce em diferentes épocas de colheita e teores (\%) médios de matéria seca (MS), fibra em detergente neutro (FDN), fibra em detergente ácido (FDA), hemicelulose (HC), proteína bruta (PB), nutrientes digestíveis totais (NDT), nitrogênio amoniacal em relação ao nitrogênio total ( $\mathrm{N}_{-} \mathrm{NH}_{3} / \mathrm{N}-\mathrm{TOTAL}$ ) e valores de $\mathrm{pH}$ de silagens de clones de batata-doce. Diamantina, MG, UFVJM, 2008.

\begin{tabular}{|c|c|c|c|c|c|c|c|c|}
\hline Clones & \multicolumn{2}{|c|}{120 dias } & \multicolumn{2}{|c|}{150 dias } & \multicolumn{2}{|c|}{180 dias } & \multicolumn{2}{|c|}{ Média } \\
\hline Braz. Rosada & \multicolumn{2}{|c|}{$14,14^{\mathrm{B}}$} & \multicolumn{2}{|c|}{$12,19^{\mathrm{B}}$} & \multicolumn{2}{|c|}{$20,68^{\mathrm{A}}$} & \multicolumn{2}{|c|}{15,67} \\
\hline Princesa & \multicolumn{2}{|c|}{$12,49^{\mathrm{B}}$} & \multicolumn{2}{|c|}{$13,10^{\mathrm{B}}$} & \multicolumn{2}{|c|}{$19,14^{\mathrm{A}}$} & \multicolumn{2}{|c|}{14,91} \\
\hline BD-08 & \multicolumn{2}{|c|}{$11,96^{\mathrm{B}}$} & \multicolumn{2}{|c|}{$13,46^{\mathrm{B}}$} & \multicolumn{2}{|c|}{$21,39^{\mathrm{A}}$} & \multicolumn{2}{|c|}{15,60} \\
\hline BD-15 & \multicolumn{2}{|c|}{$10,49^{\mathrm{B}}$} & \multicolumn{2}{|c|}{$10,70^{\mathrm{B}}$} & \multicolumn{2}{|c|}{$20,02^{\mathrm{A}}$} & \multicolumn{2}{|c|}{13,74} \\
\hline BD-25 & \multicolumn{2}{|c|}{$12,55^{\mathrm{B}}$} & \multicolumn{2}{|c|}{$13,26^{\mathrm{B}}$} & \multicolumn{2}{|c|}{$21,74^{\mathrm{A}}$} & \multicolumn{2}{|c|}{15,85} \\
\hline BD-31 TO & \multicolumn{2}{|c|}{$11,56^{\mathrm{B}}$} & \multicolumn{2}{|c|}{$10,78^{\mathrm{B}}$} & \multicolumn{2}{|c|}{$18,30^{\mathrm{A}}$} & \multicolumn{2}{|c|}{13,55} \\
\hline BD-38 & \multicolumn{2}{|c|}{$11,67^{\mathrm{B}}$} & \multicolumn{2}{|c|}{$11,89^{\mathrm{B}}$} & \multicolumn{2}{|c|}{$18,82^{\mathrm{A}}$} & \multicolumn{2}{|c|}{14,12} \\
\hline BD-45 & \multicolumn{2}{|c|}{$10,67^{\mathrm{B}}$} & \multicolumn{2}{|c|}{$11,90^{\mathrm{B}}$} & & & & \\
\hline Média & & & & & & & & \\
\hline $\mathrm{CV}$ & & & & & & & & \\
\hline Clones & MS \% & FDN \% & FDA \% & $\mathrm{HC} \%$ & PB \% & NDT \% & $\begin{array}{l}\mathrm{N}-\mathrm{NH}_{3} / \mathrm{N} \\
\text { TOTAL }\end{array}$ & $\mathrm{pH}$ \\
\hline Braz. Rosada & 20,90 & 43,83 & 37,18 & $6,65^{\mathrm{c}}$ & 11,08 & 61,98 & 3,85 & 3,77 \\
\hline Princesa & 23,09 & 46,50 & 38,40 & $8,10^{\mathrm{abc}}$ & 10,62 & 60,96 & 3,70 & 3,43 \\
\hline BD-08 & 22,01 & 45,60 & 38,43 & $7,17^{\mathrm{abc}}$ & 10,41 & 60,94 & 3,93 & 3,73 \\
\hline BD-15 & 18,48 & 45,45 & 36,50 & $8,95^{\mathrm{a}}$ & 11,32 & 62,29 & 3,13 & 3,63 \\
\hline BD-25 & 18,77 & 46,77 & 39,23 & $7,54^{\mathrm{abc}}$ & 12,07 & 60,03 & 3,52 & 3,77 \\
\hline BD-31TO & 18,51 & 46,50 & 39,43 & $7,07^{\mathrm{bc}}$ & 10,88 & 60,24 & 3,50 & 3,73 \\
\hline BD-38 & 18,67 & 47,57 & 38,90 & $8,67^{\mathrm{ab}}$ & 11,46 & 60,61 & 3,80 & 3,70 \\
\hline BD-45 & 22,76 & 47,10 & 39,05 & $8,05^{\mathrm{abc}}$ & 9,63 & 60,51 & 3,45 & 3,73 \\
\hline Média & 20,40 & 46,17 & 38,39 & 7,78 & 10,93 & 60,95 & 3,61 & 3,68 \\
\hline $\mathrm{CV}(\%)$ & 13,81 & 3,19 & 3,62 & 8,36 & 7,96 & 1,54 & 14,31 & 1,42 \\
\hline
\end{tabular}

Médias seguidas pela mesma letra maiúscula nas linhas não diferem entre si pelo teste "Tukey”, em nível de 5\% de probabilidade.

(2007) e SENGER et al. (2005) encontraram valores bem superiores para silagem de milho.

Para os teores de proteína bruta, houve uma variação de 9,63 a 12,07\%, com média de 10,93\%. Esses valores são semelhantes aos dos principais alimentos usados nas rações de aves e suínos, como farelo de arroz $(13,2 \%)$, milho $(8,26 \%)$ e sorgo baixo tanino $(9,2 \%)$ (ROSTAGNO et al., 2005). MONTEIRO et al. (2007) encontraram valores semelhantes para silagem de ramas de batata-doce, variando de 10,06 a 13,16\%. REZENDE et al. (2002) também encontraram valores semelhantes para silagem de girassol.

Em relação ao teor de NDT, todos os clones apresentaram altos valores, semelhantes às principais forrageiras. VELHO et al. (2007) encontraram valores entre 67,32 a $69,57 \%$ para silagem de milho. Os altos valores de NDT encontrados na silagem promovem um maior potencial para produção de leite e/ou carne e essa energia ingerida reduz o custo de alimentos concentrados para a suplementação da ração dos animais.
Quanto aos teores de $\mathrm{N}-\mathrm{NH}_{3}$ em relação aos teores totais de nitrogênio, todos os clones apresentaram valores baixos, variando de 3,13 a 3,93\%, com média de $3,61 \%$, indicando que a fermentação foi adequada. Segundo FERREIRA (2001), o N-NH $\mathrm{NH}_{3}$ deve ser inferior a $10 \%$ do nitrogênio total, para uma silagem de elevada qualidade.

Em relação aos valores encontrados para $\mathrm{pH}$, todos os clones encontram-se dentro do padrão ideal para silagens, com valor médio de 3,68. Resultados semelhantes de $\mathrm{pH}$ foram encontrados por MONTEIRO et al. (2007), com valores variando entre 3,8 a 4,5, em silagem de ramas de batata-doce.

\section{CONCLUSÃO}

As silagens das ramas de batata-doce apresentaram teores protéicos, energéticos e perfil fermentativo adequados, portanto, apresentam potencial para utilização na alimentação animal. 


\section{AGRADECIMENTOS}

\begin{abstract}
A Fundação de Amparo à Pesquisa do Estado de Minas Gerais (FAPEMIG), Conselho Nacional de Desenvolvimento Científico e Tecnológico (CNPq) e Coordenação de Aperfeiçoamento de Pessoal de Nível Superior (CAPES) pelas bolsas e apoios financeiros concedidos.
\end{abstract}

\section{REFERÊNCIAS}

ASSOCIATION OF OFFICIAL ANALYTICAL CHEMISTS. Official methods of analysis of the Association. Washington, 1990. 1140p.

BARREIRA, P. Batata-doce: uma das doze mais importantes culturas do mundo. São Paulo: Editora Ícone, 1986. $91 \mathrm{p}$.

CARDOSO, A.D. et al. Avaliação de clones de batata-doce em Vitória da Conquista. Horticultura Brasileira, v.23, n.4, p.911-914, 2005. Disponível em: <http://www.scielo.br/

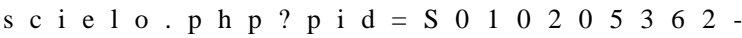
$005000400009 \&$ script $=$ sci_arttext $>$. Acesso em: 25 maio, 2011. doi: 10.1590/S0102-05362005000400009.

CONCEIÇÃO, M.K. Et al. Partição de matéria seca entre órgãos de batata-doce (Ipomoea batatas (L.) Lam), cultivares 'abóbora' e 'da costa'. Revista Brasileira Agrociência, v.10, n.3, p.313316, 2004. Disponível em: <http://www.ufpel.tche.br/faem/ agrociencia/v10n3/artigo09.pdf >. Acesso em: 25 maio, 2011.

EMBRAPA. Empresa Brasileira de Pesquisa Agropecuária. Sistema Brasileiro de Classificação de Solos. Rio de Janeiro: Embrapa Solos, 2006. 306p.

FERREIRA, J.J. Estágio de maturação ideal para ensilagem do milho e do sorgo. In: CRUZ, J.C.. et al. (Eds.). Produção e utilização de silagem de milho e sorgo. Sete Lagoas: Embrapa Milho e Sorgo, 2001. p.405-428.

FREITAS, F.C.L. et al. Formação de pastagem via consórcio de Brachiaria brizantha com o milho para silagem no sistema de plantio direto. Planta Daninha, v.23, n.1, p.49-58, 2005. Disponível em: <http://www.scielo.br/ scielo.php? script=sci arttext \& pid=S 0100 83582005000100007>. Acesso em: 25 maio, 2011. doi:10.1590/S0100-83582005000100007.

MASSAROTO, J.A. Características agronômicas e produção de silagem de clones de batata-doce. 2008 . 85f. Tese (Doutorado em Fitotecnia) - Curso de Pós-graduação em Agronomia, Universidade Federal de Lavras, MG.

MONTEIRO, A.B. Silagens de cultivares e clones de batatadoce para alimentação animal visando sustentabilidade da produção agrícola familiar. Revista Brasileira de Agroecologia, v.2, n.2, p.978-981, 2007. Disponível em: <ht tp://www.abaagroecologia.org.br/ojs $2 /$ index.php?journal $=$ rbagroecologia $\&$ page $=$ article $\&$ op $=$ viewFile $\&$ path $\% 5 \mathrm{~B} \% 5 \mathrm{D}=7066 \&$ path $\% 5 \mathrm{~B} \% 5 \mathrm{D}=5201>$. Acesso em: 25 maio, 2011.

PUPO, N.I.H. Manual de pastagens e forrageiras; formação, conservação, utilização. Campinas: ICEA, 1985. 343p.
QUEIROZ, O.C.M. et al. Silagem de cana-de-açúcar comparada a fontes tradicionais de volumosos suplementares no desempenho de vacas de alta produção. Revista Brasileira de Zootecnia, v.37, n.2, p.358-365, 2008. Disponível em: <http://www.scielo.br/ scielo.php?pid=S151635982008000200024\&script=sci_abstract \&tlng=pt $>$. Acesso em: 25 maio, 2011. doi:10.1590/S151635982008000200024.

REZENDE, A.V. et al. Avaliação do potencial do girassol (Helianthus annuus L.) como planta forrageira para ensilagem na safrinha, em diferentes épocas de cortes. Ciência e Agrotecnologia, v.35, n.5, p.1548-1553, 2002. Disponível em: <http://www.editora.ufla.br/site/_adm/upload/revista/26-E2002_23.pdf>. Acesso em: 25 maio, 2011.

ROSTAGNO, H.S. et al. Tabelas brasileiras para aves e suínos: composição de alimentos e exigências nutricionais. Viçosa: UFV, 2005. 186p.

SENGER, C.C.D. et al. Composição química e digestibilidade 'in vitro' de silagens de milho com distintos teores de umidade e níveis de compactação. Ciência Rural, v.35, n.6, p.13931399, 2005. Disponível em: <http://www.scielo.br/ scielo.php?script=sci_arttext\&pid=S010384782005000600026\&l $\mathrm{ng}=\mathrm{pt} \& \mathrm{nrm}=\mathrm{iso}>$. Acesso em: 25 maio, 2011. doi:10.1590/ S0103-84782005000600026.

SILVA, D.J.; QUEIRÓZ, A.C. De análise de alimentos (métodos químicos e biológicos). 3.ed. Viçosa: UFV, 2002. 235p.

SOUZA, A.B. Avaliação de cultivares de batata-doce quanto a atributos agronômicos desejáveis. Ciência e Agrotecnologia, v.24, n.4, p.841-845, 2000. Disponível em: <http:// www.editora.ufla.br/site/_adm/upload/revista/24-42000_02.pdf>. Acesso em: 25 maio, 2011.

VALVASORI, E. et al. Avaliação da cana-de-açúcar em substituição a silagem de milho para vacas leiteiras. Brazilian Journal of Veterinary Research and Animal Science, v.32, p.224-228, 1995. Disponível em: <http://www.editora.ufla.br/site/_adm/ upload/revista/24-4-2000_02.pdf $>$. Acesso em: 25 maio, 2011.

VAN SOEST, P.J. Use of detergents in the analyses of fibrous feeds. 2. A rapid method for the determination of fiber and lignin. Journal Association Official Analytical Chemists, v.46, p.829-835, 1967.

VELHO, J.P. et al. Composição bromatológica de silagens de milho produzidas com diferentes densidades de compactação. Revista Brasileira de Zootecnia, v.36, n.6, p.1532-1538, 2007. Disponível em: <http:// www.scielo.br/scielo.php? script $=$ sci_arttext\&pid $=$ S151635982007000700011>. Acesso em: 25 maio, 2011. doi: 10.1590/S 1516-35982007000700011.

WANDERLEY, W.L. et al. Palma forrageira (Opuntia ficus indica mill) em substituição à silagem de sorgo (Sorghum bicolor (L.) Moench) na alimentação de vacas leiteiras. Revista Brasileira de Zootecnia, v.31, n.1, p.273-281, 2002. Disponível em: <http://www.scielo.br/scielo.php?pid=S151635982002000100030\&script $=$ sci_arttext $>$. Acesso em: 25 maio, 2011. doi: 10.1590/S1516-35982002000100030. 